\title{
Engineering synergistically active and bioavailable cost-effective medicines for neglected tropical diseases; the role of excipients
}

Dolores R. Serrano ${ }^{1, \pm}$, Aikaterini Lalatsa ${ }^{2, \pm}$, M. Auxiliadora Dea-Ayuela ${ }^{3, *}$

${ }^{1}$ Departamento de Farmacia y Tecnologia Farmaceutica, Facultad de Farmacia, Universidad Complutense de Madrid, Plaza Ramon y Cajal s/n, Madrid, 28040, Spain.

${ }^{2}$ School of Pharmacy and Biomedical Sciences, University of Portsmouth, St. Michael's Building, White Swan Road, Portsmouth PO1 2DT, U.K.

${ }^{3}$ Departamento de Farmacia, Facultad de Ciencias de la Salud, Universidad Cardenal HerreraCEU, Moncada, Valencia, 46113, Spain.

${ }^{ \pm}$First co-authorship shared

*Corresponding author:

Prof María Auxiliadora Dea-Ayuela

Departamento de Farmacia, Facultad de Ciencias de la Salud

Universidad Cardenal Herrera-CEU, Moncada,

Valencia, 46113, Spain

Email: mdea@uch.ceu.es; mda_3000@yahoo.es

Tel: 961369000 | Ext. 1230

Fax: +34961395272 


\begin{abstract}
Leishmaniasis is a neglected tropical disease responsible for the ninth largest disease burden in the world threatening 350 million people mostly in developing countries. The lack of efficacy, severe adverse effects, long duration, high cost and parenteral administration of the current therapies result in poor patient compliance and emergence of resistance. Leishmaniasis' unmet need for safer, affordable and more effective treatments is only partly addressed by today's global health product pipeline that focuses on products amenable to rapid clinical development, mainly by reformulating or repurposing existing drugs for new uses. Excipients are necessary for ensuring the stability and bioavailability of currently available antileishmaniasis drugs which in their majority are poorly soluble or have severe side-effects. Thus, selection of excipients that can ensure bioavailability and safety as well as elicit a synergistic effect against the Leishmania parasites without compromising safety will result in a more efficacious, safe and fast to market medicine. We have evaluated the in vitro activity of 30 commercially available generally regarded as safe (GRAS) excipients against different Leishmania spp ., their cytotoxicity and potential use for inclusion in novel formulations. Amongst the tested excipients, the compounds with higher selectivity index were Eudragit E100 (cationic triblock copolymer of dimethylaminoethyl methacrylate, butyl methacrylate, and methyl methacrylate), CTAB (cetyltrimethylammonium bromide, cationic), lauric acid, Labrasol (non-ionic, caprylocaproyl polyoxyl-8 glycerides) and sodium deoxycholate. An ideal excipient need to possess amphiphilic nature with ionic/polar groups and possess a short or medium fatty acid chain such as lauric (C12), capric (C10) or caprylic acid (C8). Inclusion of these excipients and identification of the optimal combination of drug and excipients would lead to a more effective and safer antileishmanial therapies.
\end{abstract}

\title{
Keywords
}

Excipients, leishmaniasis, amphiphile, surfactant, lipids, Eudragit, Labrasol, medium chain fatty acids, lauric acid, sodium deoxycholate 


\section{Graphical abstract}

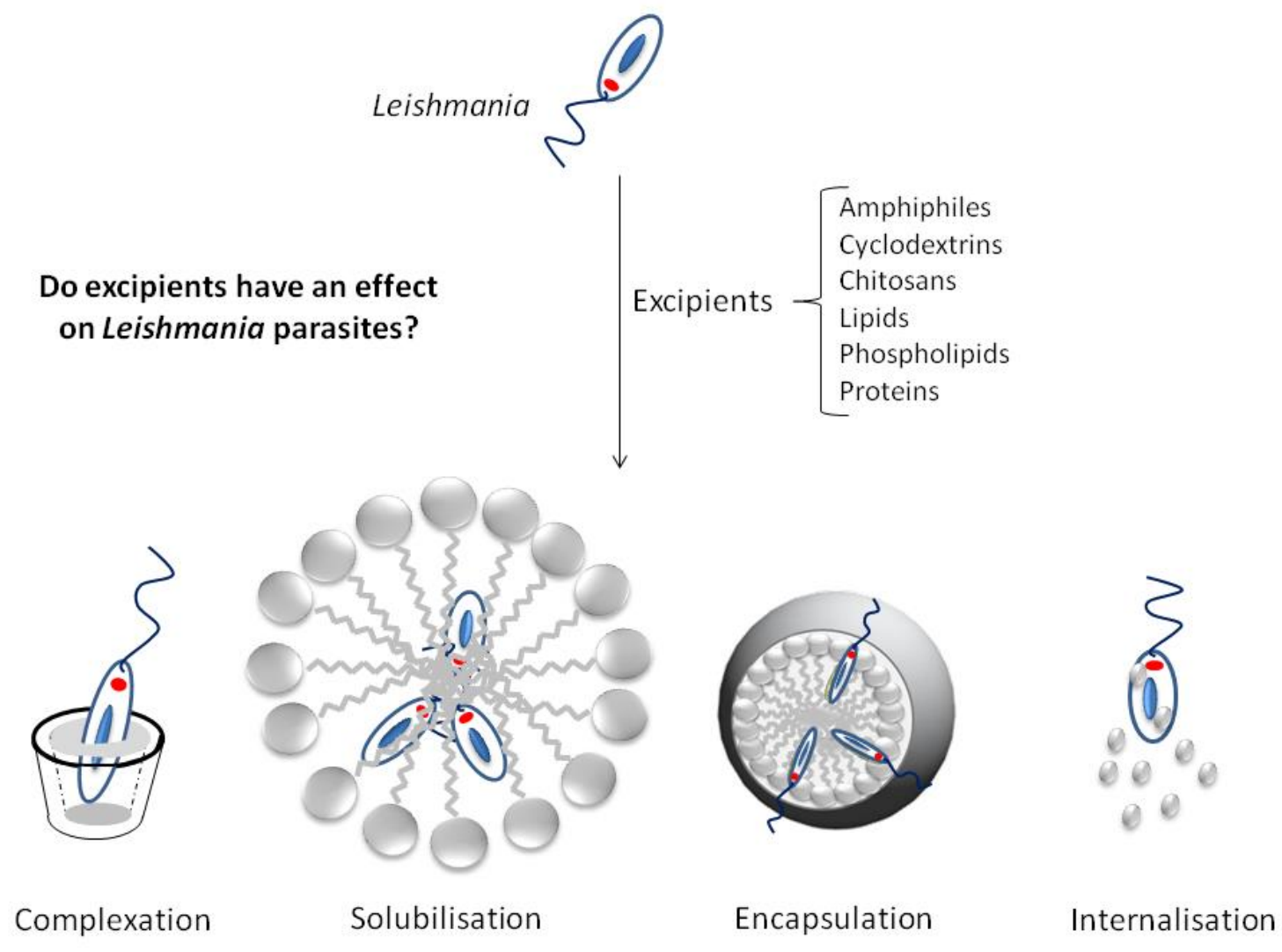




\section{Introduction}

Leishmaniasis is a neglected tropical disease responsible for the ninth largest disease burden [1]. Currently, leishmaniasis threatens 350 million men, women and children in 88 endemic areas around the world, 72 of which are developing countries with limited healthcare budgets [2]. The three major manifestations of the disease are: visceral (VL), cutaneous (CL) and mucocutaneous (MCL) leishmaniasis. CL new cases are estimated to range from 0.7 to 1.3 million while VL new cases range between 0.2 to 0.4 million according to the World Health Organisation (WHO) [3]. Patients illustrate clinical symptoms ranging from simple cutaneous lesions to mucocutaneous ulcers or systemic disease affecting vital body organs such as the liver and spleen or show a confounded severe clinical manifestation complicated by other coinfections such as HIV/AIDS [4]. The fatality rate of VL can be as high as $100 \%$ within two years if left untreated and the disease is characterised by fever, weight loss, anaemia and swelling of the spleen and liver (where parasites are located in high amounts and replicate) [2]. Although fatality rate of CL or MCL is lower compared to VL, the skin and mucous membrane lesions are debilitating resulting in serious disability and stigma leaving patients permanently scarred, unable to be employed and sometimes casted out from society $[2,3]$.

The therapeutic arsenal to treat leishmaniasis is far from ideal. Pentavalent antimonials including sodium stibogluconate (SSG) and N-methylglucamine antimoniate (meglumine antimoniate) remain the first line treatment for VL (Table 1) [5]. As resistance to antimonials is becoming more common limiting their use, emerging second-line treatments involve pentamidine and Amphotericin B (AmB). AmB administered parenterally is highly effective in VL and is available as an affordable micellar formulation (Fungizone ${ }^{\circledR}$ ) which is highly nephrotoxic limiting the dose able to be administered [6], a liposomal formulation $\left(\right.$ Ambisome $^{\circledR}$ ) which is the first line treatment in the developed world, and lipidic complexes (Amphocil ${ }^{\circledR}$ and Abelcet ${ }^{\circledR}$ ) whose use is limited further by their cost compared to Ambisome ${ }^{\circledR}$. Cost of therapy with $\mathrm{AmB}$ is also further increased by the need for cold transport and refrigeration. This has led to the clinical use of heated Fungizone ${ }^{\circledR}$ in India (prepared by 10fold dilution with water and heating to $70^{\circ} \mathrm{C}$ for 20 minutes [7]) which results in larger AmB aggregates that are not cleared by the kidneys effectively reducing observed nephrotoxicity [8]. Pentamidine, another second-line drug, has been shown to cause insulin dependent diabetes which is irreversible and potentially fatal [8]. 
Although many research efforts are focused on developing an oral amphotericin B formulation, no oral formulations are currently marketed due to its poor aqueous solubility and permeability across biological barriers $[6,9,10]$. Other clinically used medicines for leishmaniasis include paromomycin (characterised by its low cost but variable efficacy) and miltefosine. The latter, which was first licensed in India in 2003 as the first oral licensed treatment, possesses a long elimination half-life (7 days) and a narrow therapeutic index limiting the dose administered allowing for subtherapeutic levels to remain for several weeks encouraging the emergence of resistance [11]. This has already been observed in India (Bihar region that accounts alone for $50 \%$ of VL worldwide burden) and France [12]. Miltefosine has also known teratogenic effects which limits its use in women of child-bearing age and pregnant women [13].

As there is no effective vaccine for any of the ten WHO identified neglected tropical diseases including Leishmania, there is an unmet need for enhancing the efficacy, safety, compliance and affordability of available therapies as well a need to develop new medicines. To achieve this, ideally new chemical entities (NCEs) are required with enhanced potency, specificity, and lack of toxicity in order to provide breakthrough therapeutic benefits within a wide safety margin. However, they are riskier to invent than expanding the use of existing drugs by either repurposing or reformulating them or by combining them in novel fixed-dose combinations with enhanced efficacy and reduced duration of treatment.

Excipients are components of a finished drug product other than the active pharmaceutical ingredient (API) and are added during formulation for well-defined functions that can vary from facilitating the manufacture process (such as diluents, binders, lubricants), protecting the drug from physicochemical degradation (stabilisers, antioxidants), improving the bioavailability of the API (solubility and permeability across biological membranes, targeting, controlled-release). However, excipients could potentially work synergistically with the API resulting in an enhanced overall efficacy and safety of the medicine. In this study, we explore this hypothesis by assessing the in vitro activity against Leishmania spp. of 30 commercially available excipients and their cytotoxicity in order to evaluate their potential for inclusion in novel engineered dosage forms against leishmaniasis.

\section{Materials and methods}

\subsection{Materials}


Soy phosphatidylcholine (Lipoid ${ }^{\circledR}$ S 100, Batch 790611-03/906) was obtained from Lipoid GmbH (Ludwigshafen Germany). DOTAP-CL (1,2-dioleoyl-3-trimethylammonium propane) and C18:0 PEG2000 PE (1,2-distearoyl-sn-glycero-3-phosphoethanolamine, N-[methoxy(polyethylene glycol)-2000], ammonium salt) were bought from Avanti ${ }^{\circledR}$ Polars Lipids (Alabama, USA). Tripalmitin (99\% pure, Batch A009787) was purchased from Acros ${ }^{\circledR}$ Organics (Geel, Belgium). Beta-cyclodextrin (Cavamax ${ }^{\circledR}$ W7, Batch 70P470), hydroxypropylbeta-cyclodextrin $\left(\right.$ Cavasol $^{\circledR}$ W7 HP, Batch 73B025) and gamma-cyclodextrin $\left(\right.$ Cavamax $^{\circledR} \mathrm{W} 8$, Batch 80P241) were donated from Wacker Chemie AG (Munchen, Germany). Sodium deoxycholate (Batch: 30970) and hexadecyl trimethylammonium bromide (CTAB, Batch H9151) was obtained from Sigma-Aldrich. Human serum albumin (20\% w/w, Batch NCAB7EL001, also containing 0.02 M sodium caprylate and 0.02 M acetyltryptophan) was obtained from Grifols (Barcelona, Spain). Caprylocaproyl polyoxyl-8 glycerides (Labrasol ${ }^{\circledR}$, Batch 151877), oleoyl polyoxyl-6 glycerides (Labrafil ${ }^{\circledR}$ M1944 CS, Batch 110354) and diethylene glycol monoethyl ether (Transcutol ${ }^{\circledR} \mathrm{P}$, Batch 450817010) were a donated from Gattefosse (St-Priest, France). Polyvinyl caprolactam-polyvinyl acetate-polyethylene glycol graft triblock co-polymer (Soluplus ${ }^{\circledR}$, Batch 71013547G0), Poloxamer 407, a nonionic, triblock co-polymer consisting of a central hydrophobic block of polypropylene glycol flanked by two hydrophilic blocks of polyethylene glycol (Pluronic $^{\circledR}{ }^{-}$F127, $12.5 \mathrm{kDa}$, Batch 15H0651) and 2-hydroxyethyl 12-hydroxyoctadecanoate (Solutol ${ }^{\circledR} \mathrm{HS} 15$, Batch 44511588Q0) were donated from BASF (Ludwigshafen, Germany). Eudragit ${ }^{\circledR}$ E100 (cationic triblock copolymer of dimethylaminoethyl methacrylate, butyl methacrylate, and methyl methacrylate) and Eudragit ${ }^{\circledR}$ L100 (anionic diblock co-polymer based on methacrylic acic and methyl methacrylate) were donated from Evonik (Essen, Germany). Polysorbate 20, polysorbate 80, isopropyl myristate, polyethylene glycol 400 and polyethylene glycol 6000 were purchased from Panreac (Barcelona, Spain). Glycerol (molecular biology grade) was obtained from Fagron Iberica (Barcelona, Spain). Acid degraded glycol chitosan polymers of different molecular weights as illustrated in Table 2 were prepared and characterised by Dr Aikaterini Lalatsa (University of Portsmouth, Portsmouth, UK) using previously published methods [14]. Cell culture media and all other chemicals (>98\%) were purchased without further purification from Sigma-Aldrich (Dorset, UK).

\subsection{Methods}

The selected excipients were classified into the following categories according to their chemical structure and composition, ionic charge, critical micelle concentration (CMC), 
micellar size and hydrophilic-lipophilic balance (HLB) (Tables 1-4): i) Phospholipids with different ionic charges, ii) lipids (C12-C18), iii) steroids, iv) polysaccharides, v) protein carriers, vi) polymers, vii) wetting agents, viii) amphiphiles/surfactants, ix) solubilisers, $\mathrm{x}$ ) solvents.

\subsubsection{Particle size determination}

Micellar size of aqueous dispersions of amphiphiles/surfactants was determined as previously described [15]. Excipients were diluted with deionised water ( $\mathrm{pH}$ 6.5) until a final concentration of $100 \mathrm{mg} / \mathrm{ml}$ (well above their critical micelle concentration) and probe sonicated (Branson Sonifier 250, USA) for $15 \mathrm{~min}$. Mean size (nm) was measured by dynamic light scattering using a Zetatrac Ultra (Microtrac Inc, USA) with internal probe (range 0.0008 - 6.5 microns) using five runs of $60 \mathrm{~s}$ per sample and based on the size distribution by volume. Prior to measurements, polystyrene standards (diameter $=100 \mathrm{~nm}$ ) were measured; size results were in accordance with the nominal size of the standard particles.

\subsubsection{In vitro efficacy}

\section{Parasites and culture procedure}

L. braziliensis 2903 and L. amazonensis (MHOM/Br/79/Maria) [DRSL1]were kindly provided by Professor Alfredo Toraño (Instituto de Salud Carlos III, Madrid). L. donovani (MHOM-IN-80DD8) was procured from ATCC (Barcelona, Spain). These Leishmania spp. were selected because they elicit both VL (L. donovani) and cutaneous and mucocutaneous leishmaniasis $(L$. brasilensis and L. amazonensis) and also as they have shown a variable in vitro susceptibility to drugs in previous studies (L. brasiliensis was more susceptible than L. amazonensis) [16]. Promastigotes were cultured in Schneider's Insect medium supplemented with $10 \%$ heatinactivated foetal bovine serum (FBS, Sigma-Aldrich) and $1000 \mathrm{U} / \mathrm{L}$ of penicillin plus 100 $\mathrm{mg} / \mathrm{L}$ of streptomycin in $25 \mathrm{~mL}$ culture flasks at $26^{\circ} \mathrm{C}$ [17].

\section{In vitro promastigote susceptibility assays}

The in vitro activity studies were performed as previously described [18, 19]. Briefly, logphase promastigotes $\left(2.5 \times 10^{5}\right.$ parasites/well $)$ were cultured in 96-well plastic plates. All excipients were dissolved in $0.22 \mu \mathrm{m}$ filtered water at $100 \mathrm{mg} / \mathrm{ml}$ concentration except from those with poor solubility in water that were dissolved at $100 \mathrm{mg} / \mathrm{ml}$ using either in DMSO (for all the lipids, phospholipids, cholesterol and $\alpha$-tocopherol) or in DCM (for both methacrylate 
polymers). In addition, amphiphiles were probe sonicated for $15 \mathrm{~min}$ to ensure complete dispersion in deionised water. Further dilutions of the excipients using the above described medium were performed and were added up to $200 \mu \mathrm{L}$ final volume resulting in a final concentration of 200, 100, 50, 25, 12.5, 6.253 .125 and $1.065 \mu \mathrm{g} / \mathrm{ml}$ per well. Growth controls were also included. The final solvent (DMSO or DCM) concentrations never exceeded $0.5 \%$ (v/v) warranting no effect on parasites proliferation or morphology [20]. After $48 \mathrm{~h}$ at $26^{\circ} \mathrm{C}$,

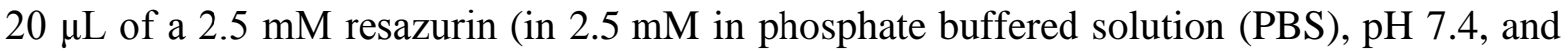
filtered through $0.22 \mu \mathrm{m}$ prior use) were added and the plates were returned to the incubator for another $3 \mathrm{~h}$. The Relative Fluorescence Units (RFU) (535 nm - $590 \mathrm{~nm}$ excitation-emission wavelength) were determined in a fluorimeter Infinite 200 (Tecan i-Control, Männedorf, Switzerland). Growth inhibition (\%) was calculated using Equation 1:

Growth inhibition $(\%)=100-\frac{\text { RFU treated wells }- \text { RFU signal to noise }}{\text { RFU untreated }-\mathrm{RFU} \text { signal to noise }} \times 100$

All tests were carried out in triplicate. Miltefosine ( $\geq 98 \%$, HPLC) dissolved in DMSO was used as the reference drug. The efficacy of each compound was estimated by calculating the $\mathrm{IC}_{50}$ (concentration of the compound that produced a 50\% reduction in parasites) and GI\% (percentage of growth inhibition at $200 \mu \mathrm{g} / \mathrm{ml}$ ).

\subsubsection{Cytotoxicity studies on murine macrophages}

Cytotoxicity tests were performed only for those excipients that possessed in vitro micromolar activity against promastigotes. As previously described, J774 murine macrophages were grown in RPMI 1640 medium supplemented with $10 \%$ heat-inactivated FBS (30 min at $56{ }^{\circ} \mathrm{C}$ ), penicillin $\mathrm{G}(100 \mathrm{U} / \mathrm{mL})$ and streptomycin $(100 \mu \mathrm{g} / \mathrm{mL})$ [17]. For the experiments, cells in the pre-confluence phase were harvested with $0.03 \%$ EDTA-0.05\% Trypsin in PBS for 20 minutes. Cell cultures were maintained at $37{ }^{\circ} \mathrm{C}$ in a humidified environment with $5 \% \mathrm{CO}_{2}$ (HucoaErlöss, Forma Scientific, Ohio, USA).

The assay was carried out as previously described [16]. J774 macrophages cell lines were seeded $\left(5 \times 10^{4}\right.$ cells/well) in 96-well flat-bottom microplates with $100 \mu \mathrm{L}$ of RPMI 1640 medium. The cells were allowed to attach for $24 \mathrm{~h}$ at $37^{\circ} \mathrm{C}, 5 \% \mathrm{CO} 2$, and the medium was replaced by different concentrations of the compounds resulting in $200 \mu \mathrm{L}$ volume with a final concentration identical to the one above described. Macrophages were exposed to the excipients for $24 \mathrm{~h}$. Growth controls were also included. Afterwards, a volume of $20 \mu \mathrm{L}$ the $2.5 \mathrm{mM}$ resazurin solution was added, and plates were incubated for another $3 \mathrm{~h}$ to evaluate 
cell viability. The reduction of resazurin was determined by the fluorescence intensity $(535 \mathrm{~nm}$ excitation wavelength and $590 \mathrm{~nm}$ emission wavelength) as in the promastigotes assay. Each concentration was assayed three times. Medium and drug controls were used in each test as blanksand the background was subtracted. Cytotoxicity of the tested compounds was defined as the $50 \%$ reduction of cell viability of treated culture cells with respect to untreated cells $\left(\mathrm{CC}_{50}\right)$. The selectivity index (SI) was calculated as expressed in Equation 2 [16]:

$$
\mathrm{SI}=\frac{C C_{50}}{I C_{50}}
$$

\section{Results and Discussion}

Selected excipients commonly used in the development of drug formulations and nanomedicines were evaluated for their in vitro efficacy against promastigotes of VL and CL causing Leishmania spp. with different susceptibility against common antileishmanial drugs [21]. Among the selected excipients, the compounds that exhibited the lowest $\mathrm{IC}_{50}$ against $L$. amazonensis were as follows: Eudragit E100 < CTAB < DOTAP-CL < sodium deoxycholate $\sim$ lauric acid < Labrasol. L. braziliensis and L. donovani was found to be more susceptible to excipients than L. amazonensis resulting in lower $\mathrm{IC}_{50}$ for tested compounds. The in vitro activity of the excipients against L. braziliensis ranked as follows: Eudragit E100 < CTAB < lauric acid < Solutol HS15 < Labrasol < sodium deoxycholate < DOTAP-CL < Tween 20. The order of excipients with activity against $L$ donovani follows a similar order to that of $L$ amazonensis with the exception of DOTAP-CL that showed no activity at the tested concentration and lauric acid that illustrated a higher $\mathrm{IC}_{50}$ (Eudragit E100 < CTAB < sodium deoxycholate < Labrasol < Tween $20<$ Solutol HS15 < lauric acid) (Table 5). The excipients illustrating the least cytotoxicity but the higher $\mathrm{CC}_{50}$ values were: stearic acid and Eudragit E100 (which showed very limited cytotoxicity at the highest tested concentration) followed by non-ionic polyethylene glycol esters (Solutol HS 15, Labrasol), anionic lipids or steroids (lauric acid, sodium deoxycholate), cationic amphiphiles (DOTAP-CL, CTAB) and polysorbate 20 (which was the most cytotoxic compound). The SI indicative of compounds with greater activity to toxicity ranked as follows: Eudragit E100 > CTAB > lauric acid > Labrasol and > sodium deoxycholate in CL causing Leishmania spp., while the SI index favours sodium deoxycholate versus CTAB in VL causing Leishmaniasis spp. (Eudragit E100> sodium deoxycholate, lauric acid, polysorbate $20>$ Solutol HS $15>$ Labrasol >CTAB). 
Solutol HS15 showed activity only against L. braziliensis and L.donovani with low cytotoxicity. As a pegylated ester of stearic acid, a saturated lipid with limited effect against promastigotes (Table 5), this is not surprisingly. However, previous studies have also illustrated the efficacy of cationic stearylamine-bearing liposomes against $L$. donovani by interaction with the surface exposed negatively charged phosphatidylserine on leishmania parasites abundant in parasitic cell membranes but not in mammalian cells [23-25].

DOTAP-CL, a cationic phospholipid quaternary ammonium chloride salt, needed higher concentrations to elicit a 50\% reduction in Leishmania promastigotes in L. braziliensis and L. donovani. However, for a cationic and quaternary ammonium amphiphile as CTAB the reverse trend was observed. The presence of a quaternary ammonium moiety ionised in physiological $\mathrm{pH}$ as observed within CTAB and DOTAP-CL as well the orally bioavailable miltefosine has been implicated for efficacy against Leishmania and Plasmodium protozoa [22]. Although the specific mechanism of action of miltefosine against Leishmania spp. is not fully understood, the mode of action of this drug is likely to be very similar as its mechanism of action against human cancer cells linking its activity mainly to apoptosis (producing reactive oxygen species resulting in DNA fragmentation, nuclear condensation and loss of cell volume), but also disturbance of membrane lipids (inhibition of phosphatidylcholine and sphingomyelin biosynthesis and ether-lipid metabolism) and inhibition of cythochrome c oxidase [26-28]. The difference in activity between DOTAP-CL and CTAB can also be explained by the fact that quaternary ammonium bromides have been shown to be more active against parasites compared to quaternary ammonium chloride salts [22, 29]. Activity of quaternary ammonium compounds can be related with its ability to inhibit water permeation through aquaporins which leads to cell death [30]. Thus, DOTAP-CL will need to be present in high amounts in liposomes or bilosomes for an antileishmanial dosage form if at all useful for a VL medicine [31].

Ionic surfactants cause disruption of the cell membrane integrity with cationic surfactants being the most cytotoxic followed by anionic and then non-ionic surfactants [32]. This is supported by the higher $\mathrm{CC}_{50}$ value of sodium deoxycholate compared to cationic CTAB and DOTAPCL [33], as cationic surfactants are known to promote destabilisation of DNA [33]. Anionic amphiphiles such as sodium deoxycholate have also shown activity against Leishmania protozoa (Table 5, IC 50 : $134 \mu \mathrm{M}$ ) and when included in Fungizone ${ }^{\circledR}$ enhance dramatically the aqueous solubility of amphotericin B by entrapment within micelles and formation of ion pairs [34]. Fungizone has an amphotericin B to deoxycholate ratio of 1:2. Amphotericin B deoxycholate systems consist of aggregates of amphotericin B-deoxycholate mixed micelles 
co-existing with pure deoxycholate micelles. When the deoxycholate concentration is subcritical for micellar formation, mixed micelles with amphotericin B are formed first as a result of the penetration of the deoxycholate molecules into the amphotericin B micelles. At higher concentrations of the surfactant molecules, the micellar structure is completely disrupted and amphotericin B is found as a monomer bound to deoxycholate. When the concentration of the surfactant is increased even further, micelles of the surfactant molecules built up. Similar results were also reported for laurylsucrose [35] and a polyoxyethylene glycol derivative of steraric acid (MYRJ 59) [36], although interaction of amphotericin B with laurylsucrose was stronger than that of sodium deoxycholate [37]. Both sodium deoxycholate and laurylsucrose enhance the selectivity of the AmB binding to sterols at exactly the concentrations of the surfactants which induce the monomerization of the antibiotic, while the maximal selectivity was found at a concentration of the surfactants corresponding to their particular CMC in presence of amphotericin B [35].

Our study is one of the first systematic studies to report on the antileishmanial activity of short and medium chain saturated fatty acids. The high reported activity of lauric acid and Labrasol against Leishmania parasites can be attributed to their ability to selective permeabilise the cell membrane resulting in a rapid and considerable membrane damage and a loss of cellular potassium and magnesium $[38,39]$. The toxicity of short chain fatty acids that affects both membrane fluidity and integrity has been previously reported on certain bacteria like E. coli and C. resinae but not against Leishmania spp [38, 39]. The rate and extent of the ion efflux is dependent on the chain length of the compounds [38, 39]. Short fatty acid chains mainly in their un-dissociated form are more soluble in water that longer chains which are more flexible and are able to permeate easier in higher concentrations in the cytoplasmic membrane and cause the disorientation of essential membrane components [38]. Also, similar effects on the intracellular membrane systems may account for the inhibition of endogenous respiration [38]. Similar to our study, lauric acid has previously illustrated dose-dependent inhibition of $L$. infantum, however a comparison with other fatty acids was not available [40]. Similarly, Labrasol (a mixed ester of capric and caprylic acid) also illustrated a high antileishmanial activity in the nanomolar range, even though Labrasol lacks a clear ionic nature due to the shielding effect provided by the polyethylene glycol (PEG) chains and possesses a larger hydrophilic head group than lauric acid [41]. It is important to note, that caprylic and capric acids are medium-chain saturated fatty acids that account for $65 \%$ and $35 \%$ of the composition of medium-chain triglycerides, which are the sources of abundant and rapidly available energy 
in the Leishmania parasite [42] especially in the stationary phases of the Leishmania spp. Longer chain lipids (stearic acid, tripalmitin), lipid esters (Labrafil) and anionic phospholipids (Soy Phosphatidylcholine, Lipoid S100) at tested concentrations did not show activity.

Short-chain triglycerides (C8) have been reported to exhibit high antimicrobial activity against Gram-positive and Gram-negative bacteria which was greater than octanoic acid [43], thus commonly using these triglycerides as food preservatives. Better incorporation within the cell membrane and the ability to form transient or permanent pores in the membrane or even solubilise membranes was reported as possible explanations for this [43, 44]. However, there is a large variation in susceptibility among different species of bacteria which can be explained by the fact that monocaprylate only integrates in specific regions of the membrane (Ld phase) depending on membrane fluidity and phospholipid composition [43]. Lipid phase coexistence (mainly Ld, liquid disordered phase and Lo, liquid ordered phase characterised by substantial amounts of cholesterol) is a phenomenon of potential biological significance $[45,46]$. The phase boundaries play a key role in membrane permeabilisation. The interface between two lipid phases has a line tension inducing packing defects at the hydrophobic interface of the lipid phase and thus, these defects increase membrane permeability [43, 47]. Lipid derivates are found to partition strongly into the Ld phases whereas polycyclic aromatic hydrocarbons with a flat ring partition preferentially into Lo phases [45]. Lipophosphoglycan (LPG) is one of the dominant surface macromolecules of the promastigote stage of all Leishmania parasitic species. LPG structural polymorphism has a significant impact on parasite survival but also in infectivity both in the sandfly vector and the mammalian host [48]. Monocaprylate can incorporate into the Ld phase of the membrane allowing to become more hydrated and thus increasing its permeabilisation [43]. The different abilities of monocaprylate to intercalate within the cellular membrane can partly explain the observed variability in the in vitro activity of lauric acid and Labrasol against all Leishmania spp.

In addition, short and medium chain fatty acids do not only possess a direct antileishmanial activity, but can also modulate the efficacy of other antileishmanial drugs altering the binding of the drugs with the sterols of the protozoa membrane. One of the major limitations of amphotericin $\mathrm{B}$ is a direct result of the binding of the drug to both cholesterol of mammalian cells as well as ergosterol of the fungal cells leading to death cell [49]. Some surfactants such as sucrose monolaurate have been previously shown to selectively decrease the binding of the amphotericin B to cholesterol without interfering with its binding to ergosterol reducing its 
toxicity and consequently, enhancing its therapeutic index [50]. However, in our study we have not tested this.

Non-ionic surfactants/amphiphiles of medium and longer fatty acid chains such as Tween 80 (Polyethylene glycol sorbitan monooleate) did not show significant activity while, polysorbate 20 (Tween 20), possesses a low SI. Although both are commonly included as a non-ionic surfactant to kinetically stabilise nanoparticulate formulations such as solid lipid nanoparticles they are not ideal to be present on the surface of particulate carriers for delivery of antileishmanial drugs.

Results from this study can guide Quality by Design (QbD) studies towards development of novel dosage forms with enhanced antileishmanial activity of existing drugs and an improved safety profile. Amphotericin B remains the first line therapy for VL due to its high efficacy and lack of resistance. Thus, selecting excipients that can enhanced AmB's oral poor aqueous solubility and permeability across biological barriers will only result in novel medicines with enhanced capability. Our results can help optimise novel strategies under research in this respect such as lipidic nanomedicines [51] or oral self-micro/nanoemulsifying drug delivery systems (SMEDDS/SNEDDS) [52, 53] such as the proposed SMEDDS (iCo-010 prepared from Glyceryl monooleate (Peceol), lauroyl macrogol-32 glyceride (Gelucire 44/14) and dalpha tocopheryl polyethylene glycol 1000 succinate (VitE-TPGS) under research for an oral AmB formulation. The latter formulations are increasingly receiving interest due to their costeffective ease of manufacture and scalability, ability to be converted from a colloidal into a solid dosage form with enhanced oral permeability and thermal stability [54]. Short and medium chain fatty acids as excipients are increasingly included within formulations of poorly soluble as well as peptide/protein drugs to increase their oral bioavailability [55-59], as well their capacity to inhibit the P-glycloprotein in the intestine which limits the oral bioavailability of many drugs [60].

Additionally, it is generally suggested that the C12 and C14 hydrophobic chains have an optimal balance of partition co-efficient and affinity for the skin [61-63], with the permeation enhancing effects for saturated fatty acids sharply increasing up to 11 carbons and reducing with increasing chain length $[64,65]$. In addition, ionic surfactants are good permeation enhancers across the stratum corneum layer which facilitates the accessibility of the drug to the parasite foci commonly located at the dermis level [66]. Thus, an ideal excipient for both oral and transcutaneous administration needs to be an amphiphile of a short or medium fatty acid 
chains (such as lauric (C12), capric (C10) or caprylic acid (C8) or their esters) with a polar head group that is ideally charged (such as a quaternary ammonium group). Our recent results as well as our previous in vitro and in vivo studies using a novel chitin derived pharmaceutical amphiphile (N-palmitoyl-N-monomethyl-N,Ndimethyl-N,N,N-trimethyl-6-O-glycolchitosan (quaternary ammonium palmitoyl glycol chitosan-GCPQ) support this [9].

\section{Conclusions}

Excipients are used for many different purposes in formulations such as API stabilisation, solubilisation, complexation or encapsulation in micro/nanoparticulate or micellar systems, with amphiphilic molecules widely used to facilitate wetting or emulsificaiton. Selection of generally regarded as safe excipients, that can ensure solubilisation, permeability across biological membranes without enhanced toxicity, can potentiate the effects of the drug within the final dosage form and allow its rapid progression in clinical trials, in order to meet the need for safer, efficacious, patient compliant drugs for the treatment of neglected tropical diseases such as leishmaniasis. Identification of optimal drug-excipient combinations can only result in better therapies and we propose the use of short and medium chain amphiphiles $(\leq 12 \mathrm{C})$ as a first point of contact for any formulator for a non-invasive treatment for leishmaniasis. 


\section{Figures:}

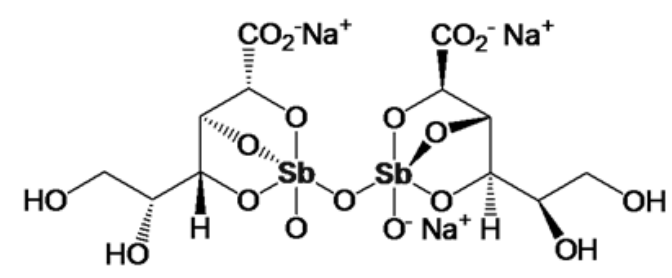

Sodium stibogluconate

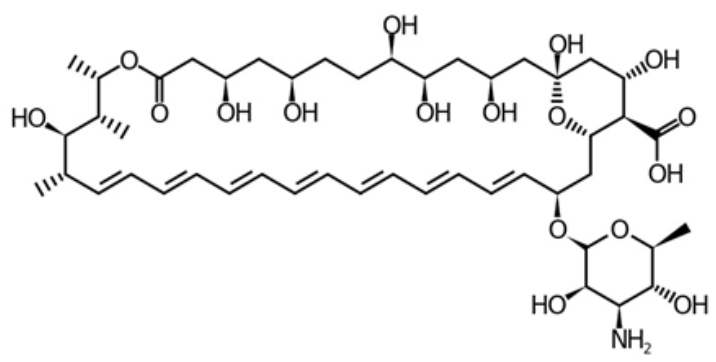

Amphotericin B

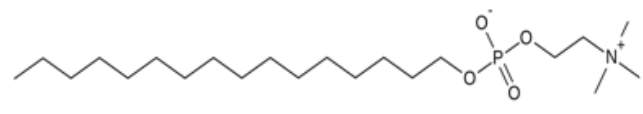

Miltefosine

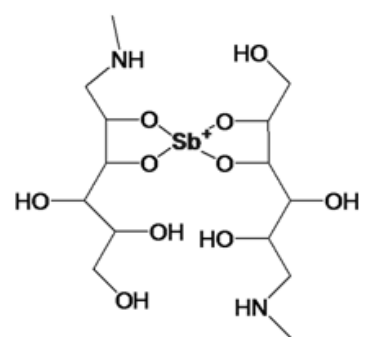

Meglumine antimoniate

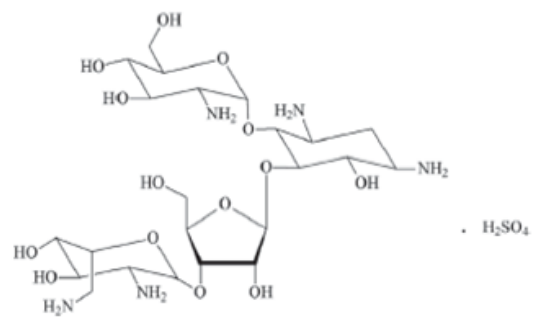

Paromomycin

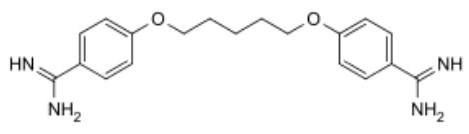

Pentamidine

Figure 1. Chemical structure of marketed antileishmanial drugs. 
Table 1. Chemical structure and characteristics of selected excipients: phospholipids, lipids and steroids.

\begin{tabular}{|c|c|c|c|c|c|}
\hline Materials & $\begin{array}{l}\text { Trade name } \\
\text { (Company) }\end{array}$ & $\begin{array}{l}\text { Molecular } \\
\text { Weight } \\
\text { (g/mol) }\end{array}$ & $\begin{array}{l}\text { Charge / } \\
\text { Neutral }\end{array}$ & Chemical structure & Ref \\
\hline \multicolumn{6}{|l|}{ Phospholipids } \\
\hline $\begin{array}{c}\text { Soybean Lecithin } \\
\text { (Phosphatidylcholine), } \\
\text { C18:2 }\end{array}$ & $\begin{array}{l}\text { Lipoid }^{\circledR} \text { S } 100 \\
\text { (Lipoid GmbH) }\end{array}$ & 800 & Anionic & & [67] \\
\hline $\begin{array}{l}\text { 1,2-dioleoyl-3-trimethylammonium } \\
\text { propane, chloride salt, } \\
\text { C18:1 }\end{array}$ & $\begin{array}{l}\text { DOTAP }- \text { CL } \\
\text { (Avanti }{ }^{\circledR} \text { Polar } \\
\text { Lipids) }\end{array}$ & 698.5 & Cationic & & [68] \\
\hline $\begin{array}{l}\text { 1,2-distearoyl-sn-glycero-3- } \\
\text { phosphoethanolamine, N-[methoxy- } \\
\text { (polyethylene glycol)-2000], ammonium } \\
\text { salt, C18:0- PEG2000 }\end{array}$ & $\begin{array}{l}\text { 18:0 PEG2000 PE } \\
\text { (Avanti }{ }^{\circledR} \text { Polar } \\
\text { Lipids) }\end{array}$ & 2805.5 & $\begin{array}{l}\text { Anionic- } \\
\text { Pegylated }\end{array}$ & & [69] \\
\hline \multicolumn{6}{|l|}{ Lipids } \\
\hline Lauric acid, C12:0 & (Sigma-Aldrich) & 200.3 & Non-ionic & & [70] \\
\hline Tripalmitin, C16:0 & $\left(\right.$ Acros Organics $\left.{ }^{\mathrm{TM}}\right)$ & 807.32 & Non-ionic & & [70] \\
\hline Stearic acid, C18:0 & (Sigma-Aldrich) & 284.5 & Non-ionic & & [70] \\
\hline \multicolumn{6}{|l|}{ Steroids } \\
\hline Cholesterol & (Sigma-Aldrich) & 386.7 & Non-ionic & & [70] \\
\hline $\begin{array}{c}\alpha \text {-Tocopherol } \\
\text { (DL- } \alpha \text {-racemic mixture) }\end{array}$ & (Sigma-Aldrich) & 472.7 & Non-ionic & & [70] \\
\hline
\end{tabular}


Table 2. Chemical structure and characteristics of selected excipients: polysaccharides, protein carriers and wetting agents.

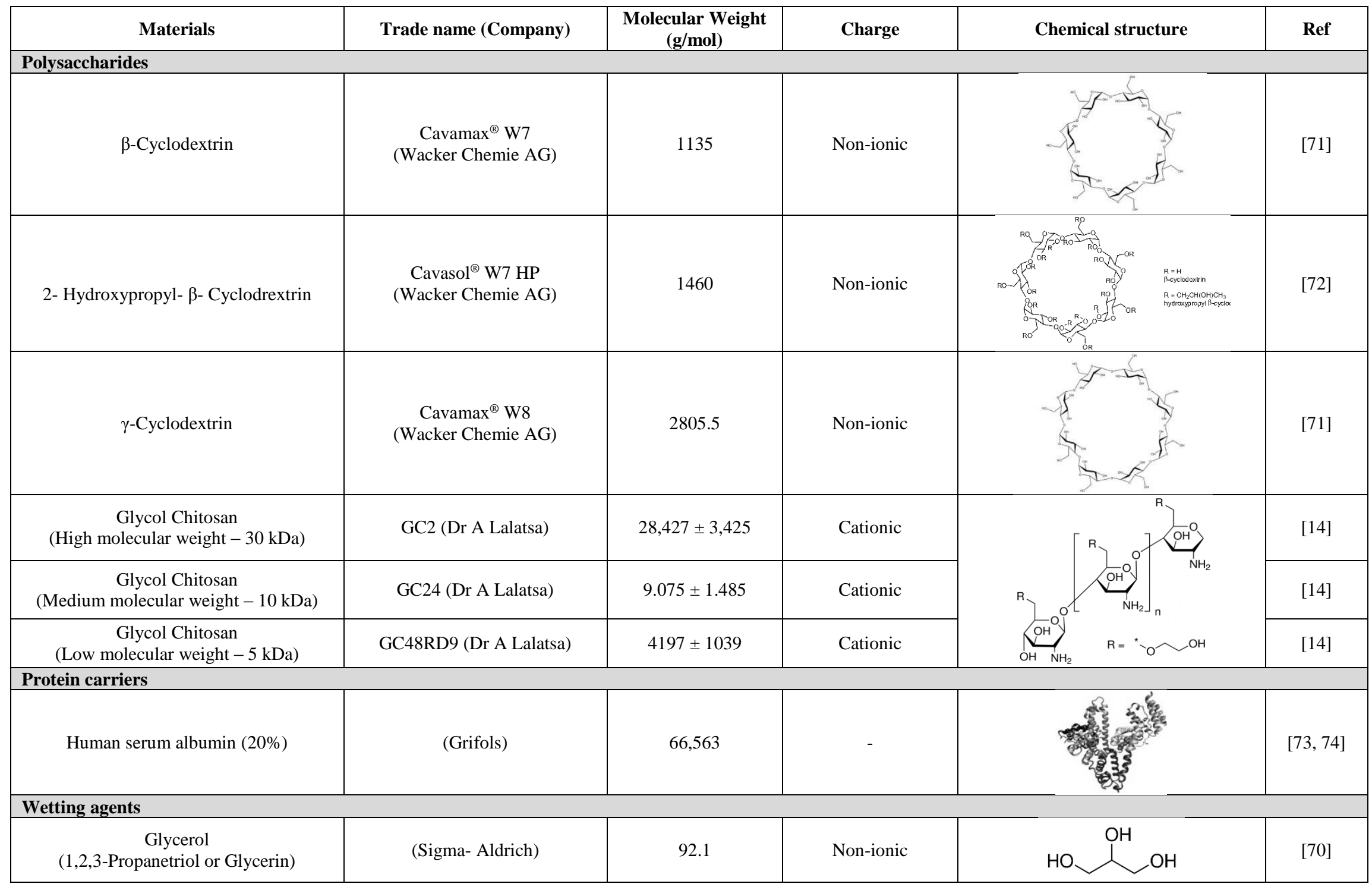


Table 3. Chemical structures and characteristics of selected amphiphiles. Micellar particle size measured by dynamic light scattering at the concentration of $100 \mathrm{mg} / \mathrm{ml}$. Key: NA, data non-available.

\begin{tabular}{|c|c|c|c|c|c|c|c|c|}
\hline Materials & $\begin{array}{l}\text { Trade name } \\
\text { (Company) }\end{array}$ & $\begin{array}{c}\text { Molecular Weight } \\
(\mathrm{g} / \mathrm{mol})\end{array}$ & Charge & Composition/ Chemical structure & $\begin{array}{c}\mathrm{CMC} \text { in } \\
\text { water at } \\
25^{\circ} \mathrm{C}\end{array}$ & $\begin{array}{c}\text { Micelle } \\
\text { size }(\mathbf{n m})\end{array}$ & $\begin{array}{l}\text { HLB } \\
\text { value }\end{array}$ & Ref \\
\hline \multicolumn{9}{|c|}{ Amphiphiles - Polyethylene glycol esters } \\
\hline $\begin{array}{c}\text { Caprylocaproyl macrogol-8 } \\
\text { glycerides } \\
\text { (PEG400 -8-Caprylic/Capric } \\
\text { Glycerides) }\end{array}$ & $\begin{array}{l}\text { Labrasol }^{\circledR} \\
\text { (Gattefosse) }\end{array}$ & $\begin{array}{l}\text { Mixture of mono-, di-, } \\
\text { and triglycerides and } \\
\text { mono- and di-fatty } \\
\text { acid esters of PEG }\end{array}$ & Non-ionic & $\begin{array}{c}\mathrm{X}=8 \& \mathrm{R}= \\
\text { Caproic acid (C6): }<2 \% \\
\text { Caprylic acid (C8): } 50-80 \% \\
\text { Capric acid (C10): } 20-50 \% \\
\text { Lauric acid (C12): }<3 \% \\
\text { Myristic acid (C14): }<1 \% \\
\end{array}$ & $0.0123 \%$ & 10.3 & 12 & $\begin{array}{l}{[75-} \\
77]\end{array}$ \\
\hline $\begin{array}{l}\text { Oleoyl macrogol-6 glycerides } \\
\text { (PEG300-6-Oleate) }\end{array}$ & $\begin{array}{l}\text { Labrafil }^{\circledR} \\
\text { M1944CS } \\
\text { (Gattefosse) }\end{array}$ & $\begin{array}{l}\text { Mixture of mono-, di-, } \\
\text { and triglycerides and } \\
\text { mono- and di-fatty } \\
\text { acid esters of PEG }\end{array}$ & Non-ionic & $\begin{array}{c}\mathrm{X}=6 \& \mathrm{R}= \\
\text { Palmitic acid (C16): } 4-9 \% \\
\text { Stearic acid (C18): }<6 \% \\
\text { Oleic acid (C18:1): 58-80\% } \\
\text { Linoleic acid (C18:2): } 15-35 \% \\
\text { Linolenic acid (C18:3): }<2 \% \\
\text { Arachidic acid (C20): }<2 \% \\
\text { Eicosenoic acid (C20:1): }<2 \%\end{array}$ & NA & 176.5 & 9 & $\begin{array}{l}{[77,} \\
78]\end{array}$ \\
\hline $\begin{array}{l}\text { Macrogol 15-hydroxystearate } \\
\text { (PEG 660 - 12-hydroxystearate) }\end{array}$ & $\begin{array}{l}\text { Solutol }{ }^{\circledR} \mathrm{HS} 15 \\
\text { (BASF) }\end{array}$ & $344.5 / 963.2$ & Non-ionic & $\begin{array}{l}\text { Mixtures of polyglycol of } \\
\text { mono- and di-esters of 12- } \\
\text { hydroxystearic acid (about } \\
70 \% \text { ) and free polyethylene } \\
\text { glycol (about } 30 \% \text { ) }\end{array}$ & $\begin{array}{l}0.005- \\
0.02 \%\end{array}$ & 9.6 & $14-16$ & $\begin{array}{l}{[79} \\
82]\end{array}$ \\
\hline \multicolumn{9}{|l|}{ Amphiphiles - Ionic surfactants } \\
\hline $\begin{array}{l}\text { Hexadecyl trimethyl ammonium } \\
\text { bromide }\end{array}$ & $\begin{array}{c}\text { CTAB } \\
\text { (Sigma-Aldrich) }\end{array}$ & 364.45 & Cationic & 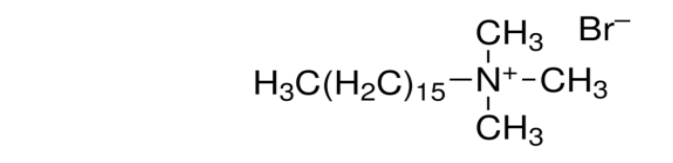 & $\begin{array}{c}0.9-1 \\
\mathrm{mM}\end{array}$ & NA & 10 & $\begin{array}{l}{[83-} \\
85]\end{array}$ \\
\hline Sodium deoxycholate & (Sigma-Aldrich) & 414.6 & Anionic & & $2-6 \mathrm{mM}$ & NA & 16 & $\begin{array}{l}{[86,} \\
87]\end{array}$ \\
\hline
\end{tabular}


Table 3 Continuation. Chemical structures and characteristics of selected polymeric excipients. Key: NA, non-available.

\begin{tabular}{|c|c|c|c|c|c|c|c|c|}
\hline Materials & $\begin{array}{l}\text { Trade name } \\
\text { (Company) }\end{array}$ & $\begin{array}{c}\text { Molecular Weight } \\
(\mathrm{g} / \mathrm{mol})\end{array}$ & Charge & Composition/ Chemical structure & $\begin{array}{c}\text { CMC in } \\
\text { water at } \\
25^{\circ} \mathrm{C}\end{array}$ & $\begin{array}{l}\text { Micelle } \\
\text { size (nm) }\end{array}$ & $\begin{array}{l}\text { HLB } \\
\text { value }\end{array}$ & Ref \\
\hline \multicolumn{9}{|l|}{ Polymers and amphiphilic polymers } \\
\hline $\begin{array}{c}\text { Polysorbate } 20 \\
\text { (Polyoxyethylene } 20 \text { sorbitan } \\
\text { monolaurate) }\end{array}$ & $\begin{array}{l}\text { Tween }{ }^{\circledR} 20 \\
\text { (Panreac) }\end{array}$ & 1228 & Non-ionic & & $\begin{array}{l}0.011-0.05 \\
\mathrm{mM}\end{array}$ & NA & 16.7 & $\begin{array}{l}{[88,} \\
89]\end{array}$ \\
\hline $\begin{array}{c}\text { Polysorbate } 80 \\
\text { (Polyoxyethylene } 20 \text { sorbitan } \\
\text { monooleate) }\end{array}$ & $\begin{array}{l}\text { Tween }{ }^{\circledR} 80 \\
\text { (Panreac) }\end{array}$ & 1310 & Non- ionic & но $x$ & $\begin{array}{c}0.012-0.018 \\
\mathrm{mM}\end{array}$ & NA & 15 & $\begin{array}{l}{[88,} \\
90]\end{array}$ \\
\hline $\begin{array}{l}\text { Polyvinyl caprolactam-polyvinyl } \\
\text { acetate polyethyleneglycol graft } \\
\text { copolymer }\end{array}$ & $\begin{array}{l}\text { Soluplus }{ }^{\circledR} \\
\text { (BASF) }\end{array}$ & $90,000-140,000$ & Non-ionic & $\begin{array}{l}\text { Vinyl caprolactam : } 57 \% \\
\text { Vinyl acetate : } 30 \% \\
\text { PEG 6000: } 13 \%\end{array}$ & $0.00076 \%$ & 55.5 & 14 & $\begin{array}{l}{[91,} \\
92]\end{array}$ \\
\hline $\begin{array}{c}\text { Poloxamer } 407 \\
\text { Poly(ethyleneoxide)/poly- } \\
\text { (propyleneoxide/poly(ethyleneoxide) } \\
\text { triblock-copolymers }\end{array}$ & $\begin{array}{l}\text { Pluronici- F127 } \\
\text { (BASF) }\end{array}$ & 12,500 & Non-ionic & $\begin{array}{l}\text { Ethyleneoxide units: } 200 \\
\text { Propyleneoxide units: } 65\end{array}$ & $0.26-0.8 \%$ & 8.9 & 22 & $\begin{array}{l}{[93,} \\
94]\end{array}$ \\
\hline Dimethylaminoethyl metacrylate & $\begin{array}{l}\text { Eudragit }{ }^{\circledR} \text { E100 } \\
\text { (Evonik) }\end{array}$ & 47,000 & Cationic & & NA & NA & NA & [95] \\
\hline
\end{tabular}




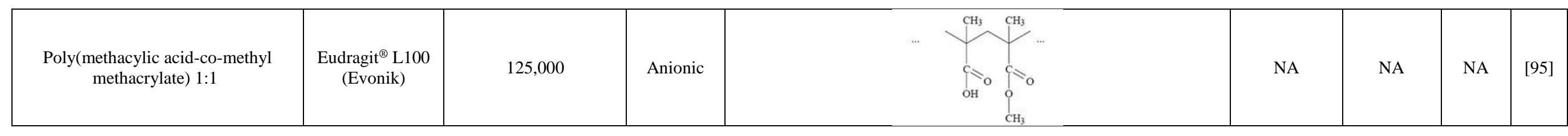

Table 4. Chemical structures and characteristics of solubilisers and solvents. Key: NA, non-applicable.

\begin{tabular}{|c|c|c|c|c|c|}
\hline Materials & $\begin{array}{l}\text { Trade name } \\
\text { (Company) }\end{array}$ & $\begin{array}{c}\text { Molecular Weight } \\
(\mathrm{g} / \mathrm{mol})\end{array}$ & Charge & Composition/ Chemical structure & Ref \\
\hline \multicolumn{6}{|l|}{ Solubilisers } \\
\hline Polyethylene glycol 400 & (Panreac) & $380-420$ & Non-ionic & & [70] \\
\hline Polyethylene glycol 6000 & (Panreac) & $570-630$ & Non-ionic & & [70] \\
\hline \multicolumn{6}{|l|}{ Solvents } \\
\hline Diethylene glycol monoethyl ether & $\begin{array}{l}\text { Transcutol }^{\circledR} \mathrm{P} \\
\text { (Gattefosse) }\end{array}$ & 134 & Non-ionic & & [96] \\
\hline Isopropyl myristate & (Panreac) & 270.47 & Non-ionic & & [70] \\
\hline Dichloromethane & (Sigma- Aldrich) & 84.9 & Non-ionic & & [70] \\
\hline
\end{tabular}


Table 5. Leishmanicidal activity of selected excipients on extracellular forms (L. amazonensis, L. braziliensis and L. donovani) and cytotoxicity on J774 macrophages. Cytotoxicity on macrophages was only determined for those excipients that showed activity against Leishmania parasites. Key: NA, non-active at the highest tested concentration $(200 \mu \mathrm{g} / \mathrm{ml}) ; \mathbf{N C}$, non-cytotoxic at the highest tested concentration $(200 \mu \mathrm{g} / \mathrm{ml}) ; \mathbf{I} \mathbf{C}_{\mathbf{5 0}}$, concentration of the excipient that produced a $50 \%$ reduction in parasites; CC $\mathbf{5 0}$, concentration of the excipient that produced a 50\% reduction of cell viability in treated culture cells with respect to untreated ones; $\mathbf{G I}(\boldsymbol{\%})$, percentage of inhibition at the highest tested concentration (200 $\mu \mathrm{g} / \mathrm{ml})$; $\mathbf{S I}$, selectivity index calculated as $\mathrm{CC}_{50} / \mathrm{IC}_{50}$; MW, molecular weight; GC, glycol chitosan. Molecular weight of Labrasol was calculated based on the specification of the US Pharmacopeia where it is stated that the mean relative molecular weight is between 200 and $400 \mathrm{~g} / \mathrm{mol}$ [97]. The calculated molecular weight of Solutol HS15 was $655.7 \mathrm{~g} / \mathrm{mol}$ which cobtained taking into account $30 \%$ of free polyethylene glycol $660(\mathrm{MW}=660 \mathrm{~g} / \mathrm{mol})$ and $70 \%$ of an equal mixture of polyglycols of mono- and di-esters of 12-hydroxystearic acid (MW= 644.5 and 963.2 $\mathrm{g} / \mathrm{mol})$.

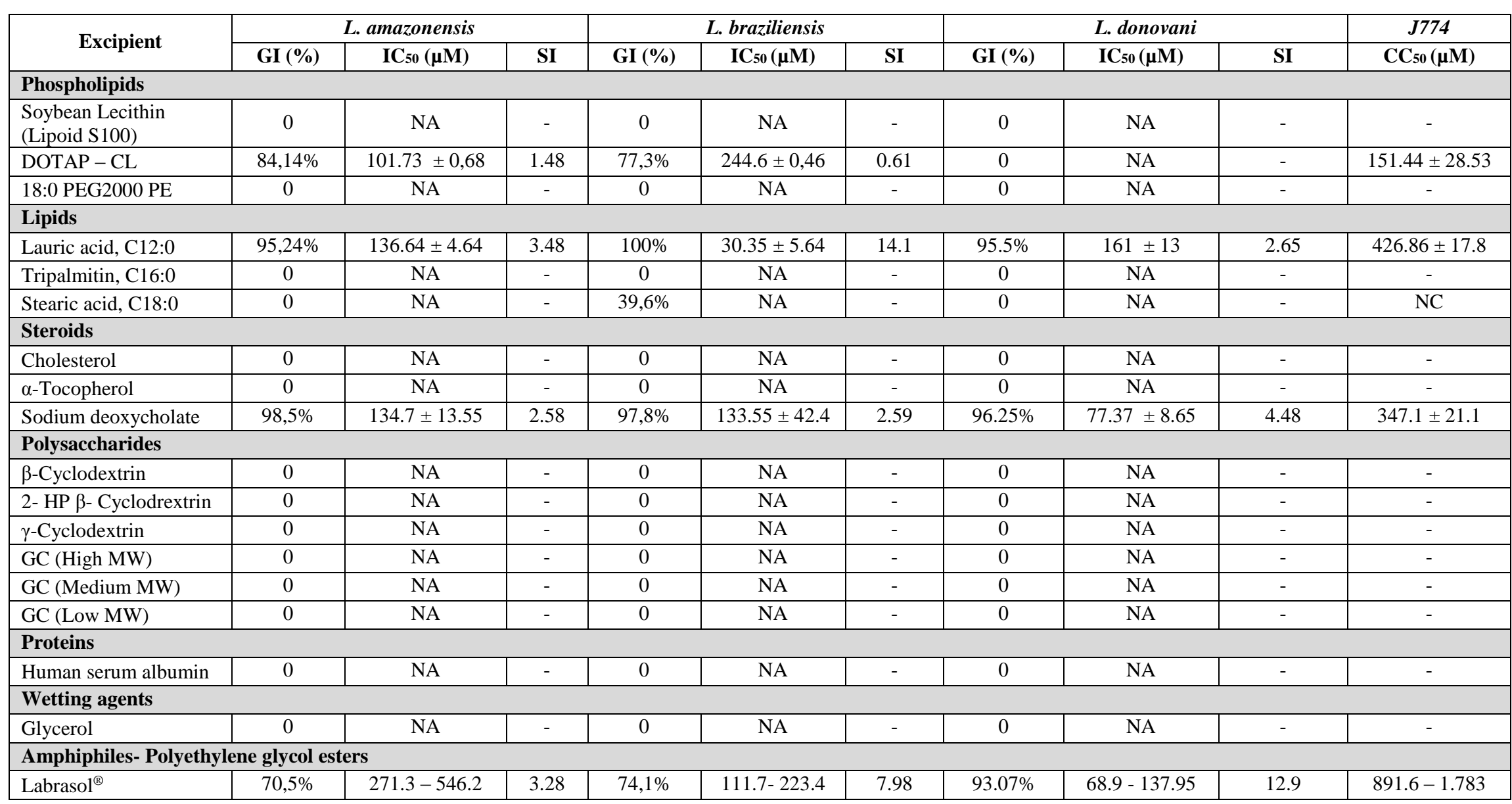




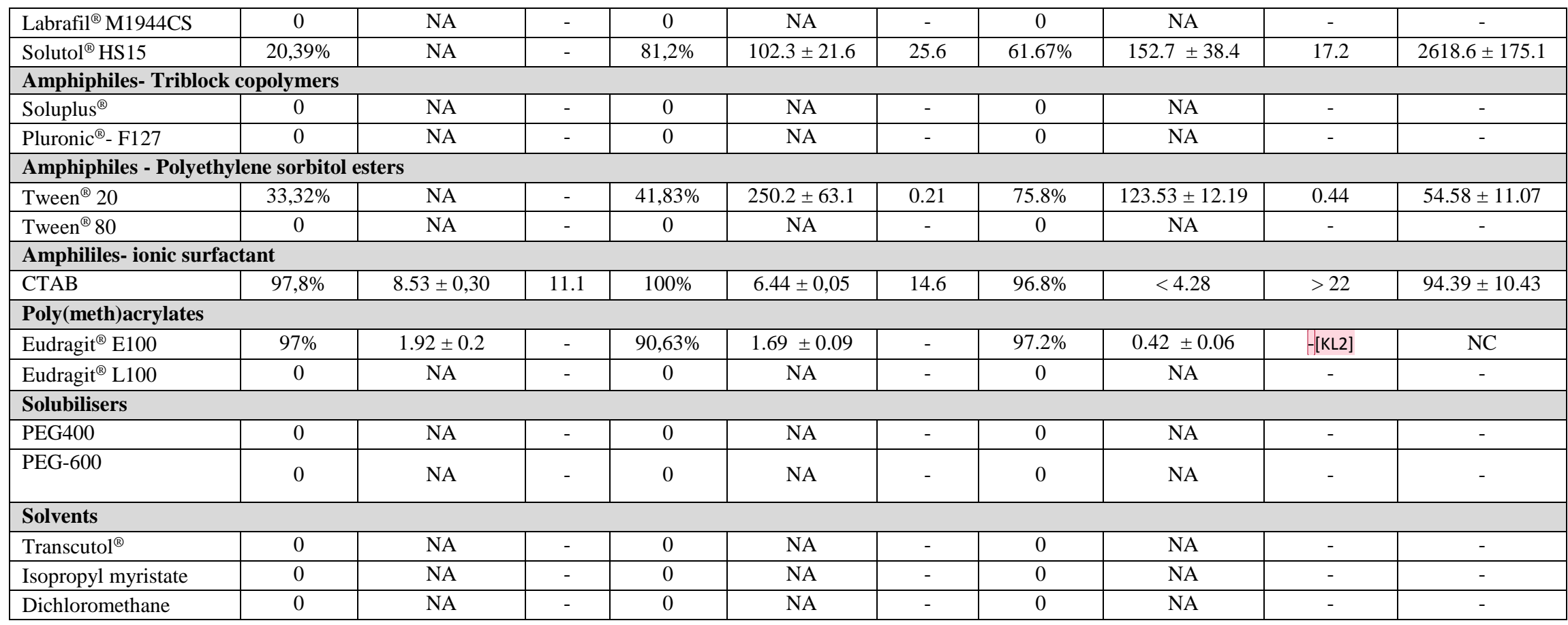




\section{References}

1. Alvar, J., et al., Leishmaniasis worldwide and global estimates of its incidence. PLoS One, 2012. 7(5): p. e35671.

2. WHO, World Health Organisation. Leishmaniasis disease and epidemiology. Available at: http://www.who.int/leishmaniasis/disease epidemiology/en/. Accessed date: 02/01/2016. 2015.

3. $\mathrm{CDC}$, Centers for disease control and prevention. Leishmaniasis. Available at: http://www.who.int/mediacentre/factsheets/fs375/en/. Accessed date: 02/01/2016. 2013.

4. Alvar, J., S. Croft, and P. Olliaro, Chemotherapy in the treatment and control of leishmaniasis. Adv Parasitol, 2006. 61: p. 223-74.

5. Frezard, F., C. Demicheli, and R.R. Ribeiro, Pentavalent antimonials: new perspectives for old drugs. Molecules, 2009. 14(7): p. 2317-36.

6. Torrado, J.J., D.R. Serrano, and I.F. Uchegbu, The oral delivery of amphotericin B. Ther Deliv, 2013. 4(1): p. 9-12.

7. Sivak, O., K. Bartlett, and K.M. Wasan, Heat-treated Fungizone retains amphotericin $B$ antifungal activity without renal toxicity in rats infected with Aspergillus fumigatus. Pharm Res, 2004. 21(9): p. 1564-6.

8. Pham, T.T., P.M. Loiseau, and G. Barratt, Strategies for the design of orally bioavailable antileishmanial treatments. Int J Pharm, 2013. 454(1): p. 539-52.

9. Serrano, D.R., et al., Oral particle uptake and organ targeting drives the activity of amphotericin B nanoparticles. Mol Pharm, 2015. 12(2): p. 420-31.

10. Santangelo, R., et al., Efficacy of oral cochleate-amphotericin $B$ in a mouse model of systemic candidiasis. Antimicrob Agents Chemother, 2000. 44(9): p. 2356-60.

11. Rijal, S., et al., Increasing failure of miltefosine in the treatment of Kala-azar in Nepal and the potential role of parasite drug resistance, reinfection, or noncompliance. Clin Infect Dis, 2013. 56(11): p. 1530-8.

12. Croft, S.L., S. Sundar, and A.H. Fairlamb, Drug resistance in leishmaniasis. Clin Microbiol Rev, 2006. 19(1): p. 111-26.

13. Sundar, S. and P.L. Olliaro, Miltefosine in the treatment of leishmaniasis: Clinical evidence for informed clinical risk management. Ther Clin Risk Manag, 2007. 3(5): p. 733-40.

14. Lalatsa, A., et al., Delivery of peptides to the blood and brain after oral uptake of quaternary ammonium palmitoyl glycol chitosan nanoparticles. Mol Pharm, 2012. 9(6): p. 1764-74.

15. Serrano, D.R., et al., Hemolytic and pharmacokinetic studies of liposomal and particulate amphotericin B formulations. Int J Pharm, 2013. 447(1-2): p. 38-46.

16. Galiana-Rosello, C., et al., In vitro and in vivo antileishmanial and trypanocidal studies of new $\mathrm{N}$-benzene- and N-naphthalenesulfonamide derivatives. J Med Chem, 2013. 56(22): p. 898498.

17. Dea-Ayuela, M.A., et al., In vivo and in vitro anti-leishmanial activities of 4-nitro-N-pyrimidinand N-pyrazin-2-ylbenzenesulfonamides, and N2-(4-nitrophenyl)-N1-propylglycinamide. Bioorg Med Chem, 2009. 17(21): p. 7449-56.

18. Adam, R., et al., Triazolopyridopyrimidines: an emerging family of effective DNA photocleavers. DNA binding. Antileishmanial activity. Org Biomol Chem, 2015. 13(17): $p$. 4903-17.

19. Bilbao-Ramos, P., et al., Nuclease activity and ultrastructural effects of new sulfonamides with anti-leishmanial and trypanocidal activities. Parasitol Int, 2012. 61(4): p. 604-13.

20. Bilbao-Ramos, P., et al., A fluorometric method for evaluation of pharmacological activity against intracellular Leishmania amastigotes. J Microbiol Methods, 2012. 89(1): p. 8-11. 
21. Ruiz, H.K., et al., New amphotericin B-gamma cyclodextrin formulation for topical use with synergistic activity against diverse fungal species and Leishmania spp. Int J Pharm, 2014. 473(1-2): p. 148-57.

22. Bahamontes-Rosa, N., et al., Monoquaternary ammonium derivatives inhibit growth of protozoan parasites. Parasitol Int, 2008. 57(2): p. 132-7.

23. Afrin, F., et al., Leishmanicidal activity of stearylamine-bearing liposomes in vitro. J Parasitol, 2001. 87(1): p. 188-93.

24. Dey, T., et al., Antileishmanial activities of stearylamine-bearing liposomes. Antimicrob Agents Chemother, 2000. 44(6): p. 1739-42.

25. Banerjee, A., J. Roychoudhury, and N. Ali, Stearylamine-bearing cationic liposomes kill Leishmania parasites through surface exposed negatively charged phosphatidylserine. J Antimicrob Chemother, 2008. 61(1): p. 103-10.

26. Dorlo, T.P., et al., Miltefosine: a review of its pharmacology and therapeutic efficacy in the treatment of leishmaniasis. J Antimicrob Chemother, 2012. 67(11): p. 2576-97.

27. Das, M., S.B. Mukherjee, and C. Shaha, Hydrogen peroxide induces apoptosis-like death in Leishmania donovani promastigotes. J Cell Sci, 2001. 114(Pt 13): p. 2461-9.

28. Verma, N.K. and C.S. Dey, Possible mechanism of miltefosine-mediated death of Leishmania donovani. Antimicrob Agents Chemother, 2004. 48(8): p. 3010-5.

29. Biagini, G.A., et al., Heme binding contributes to antimalarial activity of bis-quaternary ammoniums. Antimicrob Agents Chemother, 2003. 47(8): p. 2584-9.

30. Detmers, F.J., et al., Quaternary Ammonium Compounds as Water Channel Blockers. J Biol Chem, 2006. 281(20): p. 14207-14.

31. Kang, J.W., et al., A new vaginal delivery system of amphotericin B: a dispersion of cationic liposomes in a thermosensitive gel. J Drug Target, 2010. 18(8): p. 637-44.

32. Drobeck, H.P., Current topics in the toxicity of cationic surfactants, in Cationic surfactants: analytical and biological evaluation, J. Cross, SInger E.J., Editor. 1994, Marcel Dekker, Inc: New York. p. 75-80.

33. Bhattacharya, S. and S.S. Mandal, Interaction of surfactants with DNA. Role of hydrophobicity and surface charge on intercalation and DNA melting. Biochim Biophys Acta, 1997. 1323(1): p. 29-44.

34. Rajagopalan, N., et al., $A$ study of the solubility of amphotericin B in nonaqueous solvent systems. J Parenter Sci Technol, 1988. 42(3): p. 97-102.

35. Tancrede, P., et al., The effect of surfactants on the aggregation state of amphotericin $B$. Biochim. Biophys. Acta 1990. 1030: p. 289-295.

36. Tasset, C., V. Preat, and M. Roland, The influence of Myrj 59 on the solubility, toxicity and activity of amphotericin B. J Pharm Pharmacol, 1991. 43(5): p. 297-302.

37. Brajtburg, J. and J. Bolard, Carrier effects on biological activity of amphotericin B. Clin Microbiol Rev, 1996. 9(4): p. 512-31.

38. Teh, J.S., Toxicity of short-chain fatty acids and alcohols towards Cladosporium resinae. Appl Microbiol, 1974. 28(5): p. 840-4.

39. Royce, L.A., et al., The damaging effects of short chain fatty acids on Escherichia coli membranes. Appl Microbiol Biotechnol, 2013. 97(18): p. 8317-27.

40. Fraga, J., et al., Phylogeny of leishmania especies based-on the heat-shock protein 20 and 70 genes. Available at. http://issuu.com/clinicavet/docs/wl5 abstractbook 1/331. Accessed date: 20/01/2016.

41. Lalatsa, A., et al., Amphiphilic poly(L-amino acids) - new materials for drug delivery. J Control Release, 2012. 161(2): p. 523-36.

42. Arjmand, M., et al., Metabolomics-Based Study of Logarithmic and Stationary Phases of Promastigotes in Leishmania major by 1 H NMR Spectroscopy. Iran Biomed J, 2016. 20(2): p. 77-83. 
43. Hyldgaard, M., et al., Antimicrobial mechanism of monocaprylate. Appl Environ Microbiol, 2012. 78(8): p. 2957-65.

44. Desbois, A.P. and V.J. Smith, Antibacterial free fatty acids: activities, mechanisms of action and biotechnological potential. Appl Microbiol Biotechnol, 2010. 85(6): p. 1629-42.

45. Baumgart, T., et al., Fluorescence probe partitioning between Lo/Ld phases in lipid membranes. Biochim Biophys Acta, 2007. 1768(9): p. 2182-94.

46. Heberle, F.A. and G.W. Feigenson, Phase separation in lipid membranes. Cold Spring Harb Perspect Biol, 2011. 3(4).

47. Epand, R.M. and R.F. Epand, Domains in bacterial membranes and the action of antimicrobial agents. Mol Biosyst, 2009. 5(6): p. 580-7.

48. Forestier, C.L., Q. Gao, and G.J. Boons, Leishmania lipophosphoglycan: how to establish structure-activity relationships for this highly complex and multifunctional glycoconjugate? Forntiers in cellular and infection microbiology, 2015. 4(193): p. 1-7.

49. Torrado, J.J., et al., Amphotericin B formulations and drug targeting. J Pharm Sci, 2008. 97(7): p. 2405-25.

50. Gruda, I., et al., Effects of the detergent sucrose monolaurate on binding of amphotericin $B$ to sterols and its toxicity for cells. Biochem Biophys Res Commun, 1988. 154(3): p. 954-8.

51. Banerjee, A., M. De, and N. Ali, Complete cure of experimental visceral leishmaniasis with amphotericin B in stearylamine-bearing cationic liposomes involves down-regulation of IL-10 and favorable T cell responses. J Immunol, 2008. 181(2): p. 1386-98.

52. Wasan, K.M., et al., Novel oral amphotericin B formulation (iCo-010) remains highly effective against murine systemic candidiasis following exposure to tropical temperature. Drug Dev Ind Pharm, 2015. 41(9): p. 1425-30.

53. Wasan, E.K., et al., A novel tropically stable oral amphotericin B formulation (iCo-010) exhibits efficacy against visceral Leishmaniasis in a murine model. PLoS Negl Trop Dis, 2010. 4(12): p. e913.

54. Lalatsa, A., et al., Poster: T3145 - Oral nanomedicines for the treatment of parasitic diseases' 2014 Annual Meeting and Exposition, San Diego, United States, 2/11/14 - 6/11/14. 2014.

55. Tuvia, S., et al., A novel suspension formulation enhances intestinal absorption of macromolecules via transient and reversible transport mechanisms. Pharm Res, 2014. 31(8): p. 2010-21.

56. Brayden, D.J., J. Gleeson, and E.G. Walsh, $A$ head-to-head multi-parametric high content analysis of a series of medium chain fatty acidintestinal permeation enhancers in Caco-2 cells. Eur J Pharm Biopharm, 2014. 88(3): p. 830-39.

57. Cox, A.B., et al., In vitro interactions between the oral absorption promoter, sodium caprate $(C(10))$ and S. typhimurium in rat intestinal ileal mucosae. Pharm Res, 2008. 25(1): p. 114-22.

58. Brayden, D.J., et al., Sodium caprate-induced increases in intestinal permeability and epithelial damage are prevented by misoprostol. Eur J Pharm Biopharm, 2015. 94: p. 194206.

59. Leonard, T.W., et al., Promoting absorption of drugs in humans using medium-chain fatty acid-based solid dosage forms: GIPET. Expert Opin Drug Deliv, 2006. 3(5): p. 685-692.

60. Lin, Y., et al., Effects of Labrasol and other pharmaceutical excipients on the intestinal transport and absorption of rhodamine123, a P-glycoprotein substrate, in rats. Biol Pharm Bull, 2007. 30(7): p. 1301-7.

61. Babu, R.J., M. Singh, and N. Kanikkannan, Fatty alcohols and fatty acids, in Percutaneous Penetration Enhancers, E.W. Smith and H.I. Maibach, Editors. 2006, Taylor and Frnacis: Boca Raton.

62. Ogiso, T. and M. Shintani, Mechanism for the enhancement effect of fatty acids on the percutaneous absorption of propranolol. J Pharm Sci, 1990. 79(12): p. 1065-71. 
63. Elyan, B.M., M.B. Sidhom, and F.M. Plakogiannis, Evaluation of the effect of different fatty acids on the percutaneous absorption of metaproterenol sulfate. J Pharm Sci, 1996. 85(1): p. 101-5.

64. Oh, H.J., Y.K. Oh, and C.K. Kim, Effects of vehicles and enhancers on transdermal delivery of melatonin. Int J Pharm, 2001. 212(1): p. 63-71.

65. Kandimalla, K.K., N. Kanikkannan, and M. Singh, Optimization of a vehicle mixture for the transdermal delivery of melatonin using artificial neural networks and response surface method. J Control Release, 1999. 61(1-2): p. 71-82.

66. Som, I., K. Bathia, and M. Yasir, Status of surfactants as penetration enhancers in transdermal drug delivery. J Pharm Bioallied Sci., 2012. 4(1): p. 2-9.

67. Lipoid, Lipoid S 100 technical information. Available at: http://www.lipoid.com/en/node/105. Access date: 11/10/2015. 2015.

68. Avanti, DOTAP technical information. Available at: http://www.avantilipids.com/index.php?option=com content\&view=article\&id=946\&/temid $=156 \&$ catnumber $=890890$, Access date: 10/11/2015. 2015.

69. Avanti, 18:0 PEG2000 PE technical information. Available at: https://www.avantilipids.com/index.php?option=com content\&view=article\&id=1088\&/temi $d=448$ \&catnumber $=880120$. Accessed date: 11/10/2015. 2015.

70. The Merck Index : An Encyclopedia of Chemicals, Drugs, and Biologicals : Edition 15.

71. Wacker, Cyclodextrins technical information. Available at: http://www.wacker.com/cms/en/products/product groups/cyclodextrine 2.jsp. Accessed date: 15/12/2015. 2015.

72. Lichter, J., et al., Patent WO2010074992 A2. Controlled release auris sensory cell modulator compositions and methods for the treatment of otic disorders. 2009.

73. USP, USP monograph: Albumin (human) solution. Avalilable at: https://www.grifols.com/documents/17006/186428/albumin-25-en.pdf/34a4f904-a3164a0f-a212-f8776f7e11b8. Accessed date: 25/11/2015. 2011.

74. Li, G., D. Magana, and R.B. Dyer, Anisotropic energy flow and allosteric ligand binding in albumin. Nat Commun, 2014. 5: p. 3100.

75. Gatefosse, Labrasol technical information. Available at: http://www.gattefosse.com/media/document/tds labrasol.PDF. Accessed date: 10/12/2015. 2015.

76. Kurakula, M., et al., Chitosan based atorvastatin nanocrystals: effect of cationic charge on particle size, formulation stability, and in-vivo efficacy. Int J Nanomedicine, 2015. 10: p. 32134.

77. Strickley, R.G., Solubilizing excipients in oral and injectable formulations. Pharm Res, 2004. 21(2): p. 201-30.

78. Gattefosse, Labrafil M1944CS technical information. Available at: http://www.gattefosse.com/en/applications/labrafil-m1944cs.html. Accessed date: 20/12/2015. 2015.

79. BASF, Solutol HS15 technical information. Available at: $h$ ttp://www.pharmaingredients.basf.com/Statements/Technical\%20Informations/EN/Pharma\%20Solutions/03 0 30748e Solutol\%20HS\%2015.pdf. Accessed date: 25/12/2015. 2010.

80. Coon, J.S., et al., Solutol HS15, non-toxic polyoxyethylene esters of 12-hydroxystearic acid, reverses multidrug resistance. Cancer Research, 1991. 51: p. 897-902.

81. Vandamme, T.F. and N. Anton, Low-energy nanoemulsification to design veterinary controlled drug delivery devices. Int I Nanomedicine, 2010. 5: p. 867-73.

82. Matsaridou, I., et al., The influence of surfactant HLB and oil/surfactant ratio on the formation and properties of self-emulsifying pellets and microemulsion reconstitution. AAPS PharmSciTech, 2012. 13(4): p. 1319-30. 
83. Sigma, CTAB technical information. Available at: https://www.sigmaaldrich.com/content/dam/sigmaaldrich/docs/Sigma/Product Information Sheet/2/h6269pis.pdf. Accessed date: 25/12/2015. 2015.

84. Wei, L., et al., Self-assembly of cetyl trimethylammonium bromide in ethanol-water mixtures. Frontiers of Chemistry in China, 2006. 1(4): p. 438-442.

85. Wang, K., et al., Developing a well-adhered Ni/P alloy on the surface of silicone for shielding electromagnetic interferences, in Polymer surface modification: Relevance to adhesion, K.L. Mittal, Editor. 2009, Taylor \& Francis group: Boston. p. 301.

86. Sigma, Sodium deoxycholate technical information. Available at. http://www.sigmaaldrich.com/catalog/product/sial/d6750?lang=es\&region=ES. Accessed date: 15/12/2015. 2015.

87. Matsuoka, K. and Y. Moroi, Micelle formation of sodium deoxycholate and sodium ursodeoxycholate (part 1). Biochim Biophys Acta, 2002. 1580(2-3): p. 189-99.

88. Patist, A., et al., On the measurment of the critical micelle concentrations of pure and tehcnical grade non-ionic surfactants. Journal of surfactants and detergents, 2000. 3(1): p. 53-58.

89. Sigma, Tween 20 technical information. Available at: https://www.sigmaaldrich.com/content/dam/sigmaaldrich/docs/Sigma/Product Information Sheet/1/p5927pis.pdf. Accessed date: 02/01/2016. 2015.

90. Sigma, Tween 80 technical information. Available at: https://www.sigmaaldrich.com/content/dam/sigma-aldrich/docs/SigmaAldrich/Product Information Sheet/p8074pis.pdf. Accessed date: 02/01/2016. 2015.

91. BASF, Soluplus technical information.Available at: $h$ ttp://www. pharmaingredients.basf.com/documents/enp/brochure/en/b 03 110921e solubility enhance com pendium.pdf. Accessed date: 20/12/2015. 2010.

92. BASF, Eye on excipients. Available at: http://www.kollidon.com/Documents/ENP/Articles/EN/EyeOnExcipients 1010TC.pdf. Accessed date: 02/01/2016. 2010.

93. Gao, Q., et al., Synthesis and characterization of novel amphiphilic copolymer stearic acidcoupled F127 nanoparticles for nano-technology based drug delivery system. Colloids Surf B Biointerfaces, 2011. 88(2): p. 741-8.

94. Seth, A. and D.S. Katti, A one-step electrospray-based technique for modulating morphology and surface properties of poly(lactide-co-glycolide) microparticles using Pluronics(R). Int J Nanomedicine, 2012. 7: p. 5129-36.

95. Evonik, Eudragit porducts technical information. Available at: http://eudraqit.evonik.com/product/eudragit/en/products-services/eudragitproducts/pages/default.aspx. Accessed date: 02/01/2016. 2015.

96. Gattefosse, Transcutol technical information. Available at: http://www.gattefosse.com/media/document/tds transcutol p.PDF. Accessed date: 02/01/2016. 2015.

97. USP, Caprylocaproyl polyoxylglicerides monograph. Available at: http://www.pharmacopeia.cn/v29240/usp29nf24s0 m12363.html. Accessed date: 15/01/2016. 2010. 